\title{
Muscle oxygen consumption by NIRS and mobility in multiple sclerosis patients
}

Anna Maria Malagoni ${ }^{1,2^{*}}$, Michele Felisatti ${ }^{2}$, Nicola Lamberti ${ }^{2}$, Nino Basaglia ${ }^{3}$, Roberto Manfredini ${ }^{2,4}$, Fabrizio Salvi ${ }^{5}$, Paolo Zamboni $i^{1,2}$ and Fabio Manfredini ${ }^{2,3}$

\begin{abstract}
Background: The study of muscle metabolism by near-infrared spectroscopy (NIRS) has been poorly implemented in multiple sclerosis (MS). Aims of the study were to compare resting muscle oxygen consumption $\left(\mathrm{rmVO}_{2}\right)$ at gastrocnemius in MS patients and in age-matched healthy controls (HC) measured using NIRS, and to evaluate its possible relationship with patients' mobility.

Methods: Twenty-eight consecutively enrolled MS patients (male, $n=16$; age $=42.7 \pm 14.0$ y, Relapsing-Remitting, $\mathrm{n}=19$; Primary-Progressive, $\mathrm{n}=9$ ) and $22 \mathrm{HC}$ (male, $\mathrm{n}=13$; age $=36.0 \pm 8.2 \mathrm{y}$ ) were studied during rest applying the NIRS probes at gastrocnemius, producing a venous occlusion at the thigh using a cuff, and analyzing the slope of the total hemoglobin to calculate $\mathrm{rmVO}_{2}$. Mobility was assessed by a 6-Minute Walking Test and 6-Minute Walking Distance (6MWD) was recorded.

Results: $\mathrm{rmVO}_{2}$ was higher in MS compared to $\mathrm{HC}\left(0.059 \pm 0.038\right.$ vs $\left.0.039 \pm 0.016 \mathrm{mlO}_{2} / \mathrm{min} / 100 \mathrm{~g}, \mathrm{P}<0.003\right)$, not different in clinical subtypes, not correlated to patients' characteristics (age, disease duration, Expanded Disability Status Scale, resting heart rate, skinfold thickness), and significantly higher in patients with lower walking ability $(6 \mathrm{MWD}<450 \mathrm{~m}, \mathrm{n}=12)$ compared to those at better performance (respectively, $0.072 \pm 0.043$ vs $0.049 \pm 0.032$ $\mathrm{mlO}_{2} / \mathrm{min} / 100 \mathrm{~g}, \mathrm{P}=0.03$ ).

Conclusion: $\mathrm{rmVO}_{2}$ values, significantly higher in MS patients compared to $\mathrm{HC}$, and in low versus high performing patients, might represent a marker of peripheral adaptations occurred to sustain mobility, as observed in other chronic diseases.
\end{abstract}

Keywords: Multiple sclerosis, Muscle metabolism, Non-invasive, Near-infrared spectroscopy, Oxygen consumption

\section{Background}

Multiple Sclerosis (MS) is a neurological disorder characterized by inflammatory demyelination and neurodegeneration within the central nervous system. This condition leads to a variety of symptoms, among which reduced mobility, weakness and fatigue are common and key problems [1,2], apparently due to alterations in both central motor drive and intramuscular function [2]. The study of muscle metabolism in MS by Near-Infrared Spectroscopy (NIRS) has been poorly implemented. NIRS is a technique that allows the non-invasive study of muscle metabolism in static and dynamic conditions

\footnotetext{
* Correspondence: mlgnmr@unife.it

'Program Pathophysiology of Vascular Peripheral System, S. Anna Hospital University of Ferrara, Via A. Moro, 8, Cona, Ferrara 44124, Italy

${ }^{2}$ Vascular Diseases Center, University of Ferrara, Ferrara, Italy

Full list of author information is available at the end of the article
}

in health and disease [3-9]. A parameter that can be easily measured by NIRS is the local resting muscle oxygen consumption $\left(\mathrm{rmVO}_{2}\right)$ [10], which allows a quantification of the muscle's capacity to extract oxygen from blood. This parameter was found to be impaired in legs of patients with chronic diseases [5,7,8,11,12], and modified following exercise training in peripheral arterial disease (PAD) [13]. Therefore, $\mathrm{rmVO}_{2}$ might be potentially useful in a clinical setting for assessing the level of skeletal muscle metabolic impairment, and for detecting muscle modifications following the progression of the disease, therapeutic treatments or rehabilitative programs. We hypothesized that muscle adaptations might also occur and be detectable in MS.

This cross-sectional study aims: i) to compare the $\mathrm{rmVO}_{2}$ values at gastrocnemius collected on a sample of

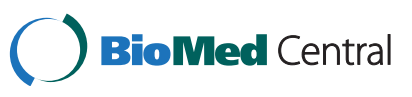


MS patients and healthy controls ( $\mathrm{HC}$ ), and evaluate possible differences in MS clinical subtypes; and ii) to evaluate possible relationships between $\mathrm{rmVO}_{2}$ values and MS patients' mobility.

\section{Methods}

\section{Subjects}

Twenty-eight MS patients referred from a regional MS were consecutively enrolled (male, $n=16$; age $=42.7 \pm$ 14.0 y). Inclusion criteria: adult patients with MS clinically defined according to the McDonald criteria [14]. Exclusion criteria: Expanded Disability Status Scale score (EDSS) > 6 [15], comorbidities affecting oxygen transport, delivery and extraction (e.g. severe anemia, PAD, etc.), acute relapse within the previous 30 days.

Twenty-two healthy age-matched adults were randomly recruited among rehabilitation laboratory staff (male, $\mathrm{n}=13$; age $=36.0 \pm 8.2 \mathrm{y}$ ). All participants gave written informed consent. The study was approved by the ethics committee of Ferrara, Italy.

\section{Resting muscle oxygen consumption by Near-Infrared Spectroscopy}

NIRS measurements were obtained with a continuous wave system (Oxymon-MK III, Artinis Medical Systems, Netherlands) providing measures of changes in oxyand deoxyhemoglobin concentrations. This system, which consists of 2 channels ( 2 equivalent pulsed light sources, 2 avalanche photodiode detectors, shielding from ambient light), uses intensity-modulated light at a frequency of 1 $\mathrm{MHz}$ and laser diodes at 3 wavelengths $(905,850$, and $770 \mathrm{~nm}$ ) corresponding to the absorption wavelengths of oxy- and deoxyhemoglobin, with an autosensing power supply (approximately $40 \mathrm{~W}$ at $110-240 \mathrm{~V}$ ). The light from the laser diodes is conducted from the instrument to the tissue and back along 3m-long optical glass fibers.

After measuring adipose tissue thickness (ATT) according to international standards [16] along the medial aspect of gastrocnemius muscle, NIRS sensors were placed at the same level. The interoptode distance was maintained at $4 \mathrm{~cm}$, allowing a maximum penetration depth of light around $20 \mathrm{~mm}$. As previously reported [12], $\mathrm{rmVO}_{2}$ was measured with the subject resting in a supine position by rapidly inflating a cuff placed around the thigh to a pressure of $60 \mathrm{mmHg}$ to obtain venous occlusion. The pneumatic cuff was quickly released after 30 seconds. The absolute $\mathrm{rmVO}_{2}$ value was calculated by the rate of increase in concentrations once the venous outflow had been blocked [17]. Data collection and calculation were performed using the software Oxysoft 47 (Artinis Medical Systems, Netherlands).

During NIRS evaluation, resting heart rate (rHR) was recorded by a heart rate monitor (Sport Tester-RS400,
Polar Electro-Oy, Kempele, Finland) and the mean value was considered for the analysis. Measurements were obtained by the same operators.

\section{Mobility assessment}

MS patients were asked to perform a 6-min walking test $(6 \mathrm{MWT})$, considered as a feasible, reproducible, and reliable measure providing sensitive information about the walking performance of persons with MS $[18,19]$. Patients were instructed to walk up and down a $22 \mathrm{~m}$ corridor at their own pace for 6 minutes, aiming to cover as much distance as possible. The distance completed after 6 minutes (6MWD) was recorded.

\section{Statistical analysis}

Data are expressed as means \pm standard deviations. The normal distribution of the data was verified by the Kolmogorov-Smirnov test. Comparison of demographics was performed using unpaired Student T-tests and Fisher's exact test, as appropriate. Differences between subgroups were measured by an unpaired Student $T$-test or One-way ANOVA test, as appropriate. A Pearson correlation was performed to evaluate the relationship between $\mathrm{rmVO}_{2}$ values in MS patients and possible influencing variables (age, disease duration, rHR, ATT). A Pearson correlation was also performed to evaluate a possible relationship between $\mathrm{rmVO}_{2}$, and EDSS, Pyramidal Functions (PF) subscale score of Kurtzke Functional Systems Scores [15], 6MWD, and rHR.

Analysis was performed considering $\mathrm{rmVO}_{2}$ values of both legs, and the mean value of the two legs of each subject, when appropriate.

Significance was set at a P-value $\leq 0.05$. Statistics were performed using MedCalc 12.4.0.0 (MedCalc Software, Mariakerke, Belgium).

\section{Results \\ Study population}

Among the MS population, 19 patients were a Relapsing Remitting (RR) clinical type, and 9 were Primary Progressive (PP). PP patients were older than $\mathrm{HC}$ and $\mathrm{RR}$ $(\mathrm{P}<0.001)$. Characteristics of study participants are presented in Table 1.

\section{Resting muscle oxygen consumption values in MS patients and healthy controls}

ATT and $\mathrm{rmVO}_{2}$ were safely measured in both legs for all MS $(n=56)$ and HC $(n=44)$. ATT was less than 20 $\mathrm{mm}$ for all participants.

$\mathrm{rmVO}_{2}$ values of both legs resulted in being significantly higher in all MS compared to healthy $(\mathrm{P}=0.003)$, even separately RR and PP $(\mathrm{P}=0.009)$ (Table 2, Figure 1). $\mathrm{PP}$ showed the highest $\mathrm{rmVO}_{2}$ values, but no significant difference with respect to RR and $\mathrm{HC}$. 
Table 1 Demographics of study participants

\begin{tabular}{lcccc}
\hline & $\begin{array}{c}\text { All MS } \\
(\mathbf{n}=\mathbf{2 8})\end{array}$ & $\begin{array}{c}\mathbf{R R} \\
(\mathbf{n}=\mathbf{1 9})\end{array}$ & $\begin{array}{c}\mathbf{P P} \\
(\mathbf{n}=\mathbf{9})\end{array}$ & $\begin{array}{c}\text { HC } \\
(\mathbf{n}=\mathbf{2 2})\end{array}$ \\
\hline Sex (n) & $M=16 ;$ & $M=10 ;$ & $M=6 ;$ & $M=13 ;$ \\
& $F=12$ & $F=9$ & $F=3$ & $F=9$ \\
Age (years) & $42.7 \pm 14.0$ & $34.2 \pm 7.6$ & $60.3 \pm 4.3^{\dagger}$ & $36.0 \pm 8.2$ \\
$\begin{array}{l}\text { Disease } \\
\text { duration (years) }\end{array}$ & $9.9 \pm 6.3$ & $7.4 \pm 3.3$ & $14.4 \pm 8.5$ & - \\
EDSS & & & & - \\
\hline
\end{tabular}

MS, Multiple Sclerosis; RR, Relapsing Remitting; PP, Primary Progressive; HC, healthy controls; EDSS, Expanded Disability Status Scale.

Not significantly higher $\mathrm{rmVO}_{2}$ values (mean of the two legs for each subject) were observed in patients with EDSS $\leq 2(n=14)$ compared to patients with EDSS $>2$ $(\mathrm{n}=14) \quad$ (respectively $0.051 \pm 0.029$ vs $0.067 \pm 0.040$ $\mathrm{mlO}_{2} / \mathrm{min} / 100 \mathrm{~g}, \mathrm{P}=$ n.s.). A similar pattern was depicted comparing $\mathrm{rmVO}_{2}$ values of patients categorized in two groups according to the PF subscale score, more strictly related to muscular functions ( $\mathrm{PF} \leq 1, \mathrm{n}=16$ vs $\mathrm{PF}>1, \mathrm{n}=12$, respectively $0.051 \pm 0.027$ vs $0.069 \pm$ $0.043 \mathrm{mlO}_{2} / \mathrm{min} / 100 \mathrm{~g}, \mathrm{P}=$ n.s.).

rHR was significantly higher in all MS patients compared to $\mathrm{HC}(\mathrm{P}=0.02)$ (Table 2$)$.

No significant relationship was found in all MS patients, and in clinical types separately, between EDSS and $\mathrm{rmVO}_{2}$ values (mean of the two legs for each subject), as well as considering the PF subscale score (mean value $=1.8 \pm 1.1)$

No significant relationships were found between the $\mathrm{rmVO}_{2}$ values of all MS patients, considering possible influencing factors (age, disease duration, rHR, ATT), even evaluating clinical types separately. In all MS a trend towards a direct relationship between $\mathrm{rHR}$ and $\mathrm{rmVO}_{2}$ (mean of the two legs for each subject) $(\mathrm{r}=0.37$, $\mathrm{P}=0.065)$ was observed.

Resting muscle oxygen consumption and mobility All MS patients performed the 6MWT. The mean value of $6 \mathrm{MWD}$ was $489.5 \pm 194.0 \mathrm{~m}$.

Table 2 Values of main parameters recorded in study participants

\begin{tabular}{lcccc}
\hline & $\begin{array}{c}\text { All MS } \\
(\mathbf{n}=\mathbf{2 8})\end{array}$ & $\begin{array}{c}\text { RR } \\
(\mathbf{n}=\mathbf{1 9})\end{array}$ & $\begin{array}{c}\text { PP } \\
(\mathbf{n}=\mathbf{9})\end{array}$ & $\begin{array}{c}\text { HC } \\
(\mathbf{n}=\mathbf{2 2})\end{array}$ \\
\hline Legs (n) & 56 & 38 & 18 & 44 \\
$\mathbf{r m V O}_{\mathbf{2}}\left(\mathbf{m l O}_{2} /\right.$ & $0.059 \pm$ & $0.058 \pm$ & $0.060 \pm$ & $0.039 \pm$ \\
$\mathbf{m i n} / \mathbf{1 0 0 g})$ & $0.038^{*}$ & $0.043^{\dagger}$ & $0.025^{\dagger}$ & 0.016 \\
$\mathbf{r H R}$ (beats/min) & $85 \pm 10^{*}$ & $83 \pm 11$ & $89 \pm 8$ & $79 \pm 6$ \\
\hline
\end{tabular}

MS, Multiple Sclerosis; RR, Relapsing Remitting; PP, Primary Progressive; HC healthy controls; $\mathrm{rmVO}_{2}$, resting muscle oxygen consumption; rHR, resting heart rate.

${ }^{*} \mathrm{P}<0.05$ by Unpaired Student $T$-test between all $\mathrm{MS}$ and $\mathrm{HC}$

${ }^{+} \mathrm{P}<0.05$ by One way-ANOVA among RR, PP, and HC.

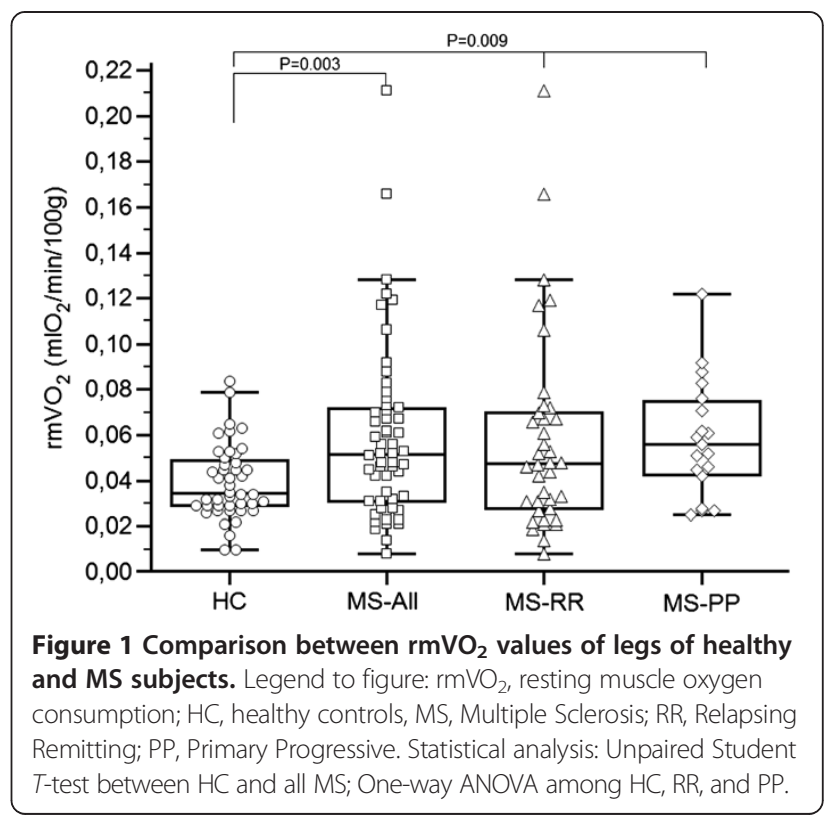

On the basis of the mean walking speed of healthy individuals of the same age $(1.26 \mathrm{~m} / \mathrm{sec})$ [20], patients were categorized in two groups, a group of lower walking ability ( $\mathrm{n}=12, \mathrm{PP}, \mathrm{n}=9, \mathrm{RR}, \mathrm{n}=3$ ) and a group of better performance $(\mathrm{n}=16, \mathrm{RR}, \mathrm{n}=16, \mathrm{PP}, \mathrm{n}=0)$ ), considering a cut-off in 6MWD equal to $450 \mathrm{~m}$.

The group of lower walking ability showed significantly higher $\mathrm{rmVO}_{2}$ values of both legs compared to the group of better performance $(\mathrm{P}=0.03)$ (Table 3$)$, and healthy controls $(\mathrm{P}<0.001)$ (Figure 2$)$. As additional observation, the same significant difference was highlighted considering the rHR $(\mathrm{P}<0.004)$ (Table 3$)$. Furthermore, in the entire MS population, 6MWD was also found inversely correlated to $\mathrm{rHR}(\mathrm{r}=-0.44, \mathrm{P}=0.02)$, whilst no correlation was found with $\mathrm{rmVO}_{2}$ values (mean of the two legs for each subject).

\section{Discussion}

The present study, to the best of our knowledge, for the first time deals with the measurement of $\mathrm{rmVO}_{2}$ by

Table 3 Comparison between the two subgroups of MS patients according to walking performance

\begin{tabular}{lccc}
\hline & $\begin{array}{c}\text { MS Low performance } \\
(\mathbf{6 M W D}<\mathbf{4 5 0} \mathbf{~ m}) \\
(\mathbf{n}=\mathbf{1 2})\end{array}$ & $\begin{array}{c}\text { MS High performance } \\
(\mathbf{6 M W D}>\mathbf{4 5 0} \mathbf{m}) \\
(\mathbf{n}=\mathbf{1 6})\end{array}$ & $\begin{array}{c}\mathbf{P} \\
\text { value }\end{array}$ \\
\hline Legs (n) & 24 & 32 & \\
$\mathbf{6 M W D}(\mathbf{m})$ & $294.3 \pm 106.8$ & $636.6 \pm 70.5$ & $<0.0001$ \\
$\mathbf{r m V O}_{\mathbf{2}}\left(\mathbf{m l O}_{\mathbf{2}} /\right.$ & $0.072 \pm 0.043$ & $0.049 \pm 0.032$ & $=0.03$ \\
$\mathbf{m i n} / \mathbf{1 0 0 g})$ & & & $<0.004$ \\
$\mathbf{r H R}$ & $91 \pm 9$ & $81 \pm 9$ & \\
(beats/min) & & &
\end{tabular}

MS, Multiple Sclerosis; 6MWD, 6 Minute Walking Distance; $\mathrm{rmVO}_{2}$, resting muscle oxygen consumption; rHR, resting heart rate. 


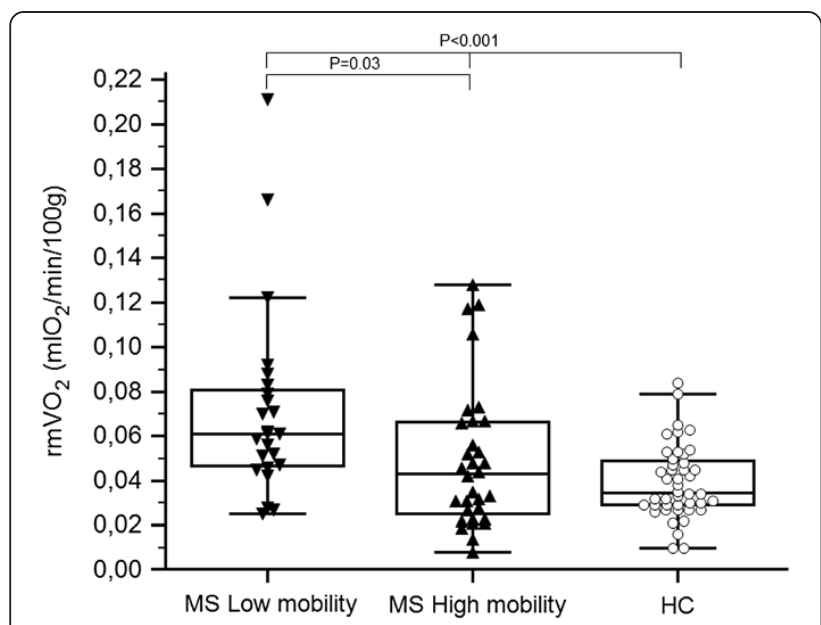

Figure 2 Comparison between $\mathrm{rmVO}_{2}$ values of legs of MS population ranked according to mobility. Values of healthy controls were also included. Legend to figure: $\mathrm{rmVO}_{2}$, resting muscle oxygen consumption; MS, Multiple Sclerosis; $\mathrm{HC}$, healthy controls. Statistical analysis: Unpaired Student T-test between MS low and high mobility; One-way ANOVA among MS low and high mobility, and HC.

NIRS in MS patients. This parameter determined by venous occlusion was found to be significantly higher in MS patients than in healthy subjects, in absence of differences between clinical subtypes, EDSS and PF subscale scores, and with no correlation to patients' age, disease duration, rHR, ATT, EDSS, and PF subscale score. Interestingly, low performing patients showed higher $\mathrm{rmVO}_{2}$ values compared to better performing subjects, as well as a higher resting heart rate.

The $\mathrm{rmVO}_{2}$ parameter was also studied in some other patients with chronic diseases, such as chronic heart failure (CHF) [11] and PAD [12]. Lower $\mathrm{rmVO}_{2}$ values at brachioradialis muscle have been observed in patients with CHF compared to healthy subjects [11]. Just in another population with walking impairment as PAD patients, compared to healthy subjects, did we observe $\mathrm{rmVO}_{2}$ values at gastrocnemius by venous occlusion, which were significantly higher in more severely diseased patients [12], similar to those observed in the present MS population. In that case a possible compensatory mechanism to the lack of oxygen has been hypothesized. To support this hypothesis of plastic peripheral adaptations in the $\mathrm{O}_{2}$ system, different $\mathrm{rmVO}_{2}$ values were observed in the legs of PAD patients after a 6month exercise program, with increased values in limbs without hemodynamic improvements and lower changes (decrease) in the limbs less ischemic following rehabilitation [13].

In MS patients where blood flow restrictions are not present, an abnormal pattern of muscle fiber composition and size with respect to healthy people has been observed, with fewer type I fibers, a shift towards white fibers, and smaller fibers of all types [2]. This picture seems to be consistent with the pattern described in subjects exposed to deconditioning [2]. In a group of chronic stroke survivors, values of $\mathrm{rmVO}_{2}$ superimposable to those observed in MS patients were observed in the hemiplegic leg, with a decrease to reach the lower values of the unaffected limb after 10 weeks of overground gait training (unpublished data).

Therefore, it seems that a pathological (neurologic or vascular) condition plus a deconditioning phase is responsible for an adaptive increase of this parameter.

However, skeletal muscle energetic status during rest does not seem significantly impaired in MS compared to healthy subjects, with no indication of metabolic inflexibility or mitochondrial dysfunction [21], thus with a likely normal adaptive attitude. Our results in MS patients might be explained assuming that the residual type I fibers develop a greater metabolic activity and enhanced capillarization as a compensatory mechanism to sustain walking endurance capacity and fatigue. Otherwise, variation in artero-venous difference is a factor influencing $\mathrm{rmVO}_{2}$ together with the blood flow, per se, potentially supported by the higher rHR observed in MS patients, and more in lower performing ones, compared to $\mathrm{HC}$.

This preliminary study, with its limitations due to the small sample size and NIRS technique (limited region of muscle evaluated, variability of probe position, ATT, etc.), sheds some light on non-invasive muscle evaluation by NIRS in MS. $\mathrm{rmVO}_{2}$ at gastrocnemius, a quick and painless measurement suitable for a clinical setting [12], might represent a biomarker of peripheral adaptations related to patients' mobility. It was found to be stable in repeated measurements in normally active, healthy subjects, and modified following 6-month training in PAD patients with a different adaptive response according to the hemodynamic changes observed in each leg [13]. Along these lines, investigations into $\mathrm{rmVO}_{2}$ might be an interesting issue in MS, for the purpose of monitoring rehabilitative programs. In the present study, we focused on gastrocnemius, based on previous experience [12,13], and its relation to mobility. However, other muscle groups can also be measured to observe whether changes in $\mathrm{rmVO}_{2}$ occur in MS during the progression of the disease or in response to treatments.

\section{Conclusions}

$\mathrm{rmVO}_{2}$ values measured by NIRS were found to be significantly higher in MS patients compared to $\mathrm{HC}$, and in low versus better performing patients. Such parameter might represent a marker of peripheral adaptations occurred to sustain mobility. It might be potentially useful in a clinical setting for assessing the level of skeletal muscle metabolic impairment, and for monitoring the 
progression of the disease, therapeutic treatments or rehabilitative programs.

\section{Abbreviations}

ATT: Adipose tissue thickness; EDSS: Expanded disability status scale score; HC: Healthy controls; MS: Multiple sclerosis; NIRS: Near-infrared spectroscopy; PAD: Peripheral arterial disease; PF: Pyramidal functions subscale score; PP: Primary progressive; $r \mathrm{HR}$ : Resting heart rate; $\mathrm{rmVO}_{2}$ : Resting muscle oxygen consumption; RR: Relapsing remitting.

\section{Competing interests}

The authors declare that they have no competing interests.

\section{Authors' contributions}

AMM, conceived and designed the study, collected the data, analyzed and interpreted the data, drafted the manuscript; MF, collected the data, analyzed and interpreted the data; $\mathrm{NL}$, collected the data, analyzed and interpreted the data; NB, participated in the design of the study and revised the manuscript; RM, participated in the design of the study and revised the manuscript; FS, participated in the design of the study and revised the manuscript; PZ designed the study, analyzed and interpreted the data, and critically revised the manuscript; FM, conceived and design the study, analyzed and interpreted the data, drafted and critically revised the manuscript. All authors read and approved the final manuscript.

\section{Acknowledgments}

This study was supported by a Funds PRIN 2010 Italian Ministry of University and Research and Ricerca ed Innovazione Regione Emilia e Romagna 2012, Italy.

\section{Author details}

${ }^{1}$ Program Pathophysiology of Vascular Peripheral System, S. Anna Hospital University of Ferrara, Via A. Moro, 8, Cona, Ferrara 44124, Italy. ${ }^{2}$ Vascular Diseases Center, University of Ferrara, Ferrara, Italy. ${ }^{3}$ Department of Rehabilitation Medicine, S. Anna Hospital, Ferrara, Italy. ${ }^{4}$ Clinica Medica, Department of Medical Sciences, University of Ferrara, Ferrara, Italy. ${ }^{5}$ Center for Rare and Neuroimmunological Diseases, Department of Immunological Science, Bellaria Hospital, Bologna, Italy.

Received: 20 December 2012 Accepted: 3 May 2013 Published: 29 May 2013

\section{References}

1. Newman MA, Dawes H, van den Berg M, Wade DT, Burridge J, Izadi H: Can aerobic treadmill training reduce the effort of walking and fatigue in people with multiple sclerosis: a pilot study. Mult Scler 2007, 13:113-119.

2. Kent-Braun JA, Ng AV, Castro M, Weiner MW, Gelinas D, Dudley GA, Miller RG: Strength, skeletal muscle composition, and enzyme activity in multiple sclerosis. J App/ Physio/ 1997, 83:1998-2004.

3. Mancini DM, Bolinger L, Li H, Kendrick K, Chance B, Wilson JR: Validation of near-infrared spectroscopy in humans. J Appl Physiol 1994, 77:2740-2747

4. Ferrari M, Binzoni T, Quaresima V: Oxidative metabolism in muscle. Philos Trans R Soc Lond B Biol Sci 1997, 352:677-683.

5. Boushel R, Langberg H, Olesen J, Gonzales-Alonzo J, Bülow J, Kjaer M: Monitoring tissue oxygen availability with near infrared spectroscopy (NIRS) in health and disease. Scand J Med Sci Sports 2001, 11:213-222.

6. Ferrari M, Mottola L, Quaresima V: Principles, technique and limitations of near-infrared spectroscopy. Can J Appl Physiol 2004, 29:463-487.

7. Hamaoka T, McCully KK, Quaresima V, Yamamoto K, Chance B: Near-infrared spectroscopy/imaging for monitoring muscle oxygenation and oxidative metabolism in healthy and diseased humans. J Biomed Opt 2007, 12:062105

8. Grassi B, Marzorati M, Lanfranconi F, Ferri A, Longaretti M, Stucchi A, Vago P, Marconi C, Morandi L: Impaired oxygen extraction in metabolic myopathies: detection and quantification by near-infrared spectroscopy. Muscle Nerve 2007, 35:510-520.

9. Manfredini F, Malagoni AM, Felisatti M, Mandini S, Mascoli F, Manfredini R, Basaglia N, Zamboni P: A dynamic objective evaluation of peripheral arterial disease by near-infrared spectroscopy. Eur J Vasc Endovasc Surg 2009, 38:441-448.
10. Van Beekvelt MC, Colier WN, Wevers RA, Van Engelen BG: Performance of near-infrared spectroscopy in measuring local $\mathrm{O}(2)$ consumption and blood flow in skeletal muscle. J Appl Physiol 2001, 90:511-519.

11. Abozguia K, Phan TT, Shivu GN, Maher AR, Ahmed I, Wagenmakers A, Frenneaux MP: Reduced in vivo skeletal muscle oxygen consumption in patients with chronic heart failure-a study using Near Infrared Spectrophotometry (NIRS). Eur J Heart Fail 2008, 10:652-657.

12. Malagoni AM, Felisatti M, Mandini S, Mascoli F, Manfredini R, Basaglia N, Zamboni P, Manfredini F: Resting muscle oxygen consumption by near-infrared spectroscopy in peripheral arterial disease: a parameter to be considered in a clinical setting? Angiology 2010, 61:530-536.

13. Manfredini F, Malagoni AM, Mandini S, Felisatti M, Mascoli F, Basaglia N, Manfredini R, Mikhailidis DP, Zamboni P: Near-infrared spectroscopy assessment following exercise training in patients with intermittent claudication and in untrained healthy subjects. Vasc Endovascular Surg 2012, 46:315-324.

14. Polman $\mathrm{CH}$, Reingold SC, Edan G, Filippi M, Hartung HP: Diagnostic criteria for multiple sclerosis: 2005 revisions to the "McDonald Criteria". Ann Neurol 2005, 58:840-846.

15. Kurtzke JF: Rating neurologic impairment in multiple sclerosis: an expanded disability status scale (EDSS). Neurology 1983, 33:1444-1452.

16. Marfell-Jones M, Olds T, Stewart A, Carter L: International standards for anthropometric assessment. Potchefstroom, South Africa: International Society for the Advancement of Kinanthropometry; 2006.

17. De Blasi RA, Almenrader N, Aurisicchio P, Ferrari M: Comparison of two methods of measuring forearm oxygen consumption (VO2) by near infrared spectroscopy. J Biomed Optics 1997, 2:171-173.

18. Goldman MD, Marrie RA, Cohen JA: Evaluation of the six-minute walk in multiple sclerosis subjects and healthy controls. Mult Scler 2008, 14:383-390.

19. Motl RW, Suh Y, Balantrapu S, Sandroff BM, Sosnoff JJ, Pula J, et al: Evidence for the different physiological significance of the 6- and 2-min walk tests in multiple sclerosis. BMC Neurol 2012, 12:6.

20. Schimpl M, Moore C, Lederer C, Neuhaus A, Sambrook J, Danesh J, Ouwehand W, Daumer M: Association between walking speed and age in healthy, free-living individuals using mobile accelerometry-a crosssectional study. PLoS One 2011, 6:e23299.

21. Mähler A, Steiniger J, Bock M, Brandt AU, Haas V, Boschmann M, Paul F: Is metabolic flexibility altered in multiple sclerosis patients? PLOS One 2012, 7:e43675.

doi:10.1186/1471-2377-13-52

Cite this article as: Malagoni et al:: Muscle oxygen consumption by NIRS and mobility in multiple sclerosis patients. BMC Neurology 2013 13:52.

\section{Submit your next manuscript to BioMed Central and take full advantage of:}

- Convenient online submission

- Thorough peer review

- No space constraints or color figure charges

- Immediate publication on acceptance

- Inclusion in PubMed, CAS, Scopus and Google Scholar

- Research which is freely available for redistribution 